\title{
Neuer Service für alle FMH-Mitglieder
}

Die Ärztekammer der FMH hat am 26. Oktober 2011 beschlossen, die drei Kernzeitschriften des Schweizerischen Ärzteverlages durch ein Sockelabonnement zu unterstützen: Schweizerische Ärztezeitung, Schweizerisches Medizin-Forum und Swiss Medical Weekly. Das Swiss Medical Weekly ist eine wissenschaftliche Zeitung, die sich als Plattform für den Schweizer akademischen Nachwuchs einsetzen will. Es ist eine Online-Zeitschrift, die open access erscheint, und liegt damit im Trend der universitär gewünschten Publikationen.
Wir sind überzeugt, dass die Inhalte des SMW, insbesondere die verschiedenen Reviews in den Sektionen «medical intelligence», «current opinion» und «medtech», viele FMH-Mitglieder ansprechen werden. Alle haben ein akademisches Studium hinter sich, bilden sich regelmässig weiter und werden diese einfachen, übersichtlichen und kondensierten Appetizer sicher zu schätzen wissen.

Wissenschaft begleitet die Ärztin und den Arzt nicht nur im Studium und in der Weiterbildung, sondern auch in der Fortbildung. Das SMW ist nicht

\section{Der Leser soll sich rasch ein Bild machen, ob er im Internet den ganzen Artikel lesen möchte.}

Seit Anfang 2013 gibt es eine neue Printversion des SMW, die unverändert die «extended abstracts» der Originalarbeiten und neu eine journalistisch verarbeitete Zusammenfassung der «reviews» beinhaltet. Dies soll dem Leser erlauben, sich rasch ein Bild zu machen, ob und wofür er sich im Internet den ganzen Artikel anschauen möchte. Diese neue Printversion erscheint als zweiter Teil zusammen mit dem Schweizerischen Medizin-Forum und erreicht somit jede Woche alle FMH-Mitglieder.

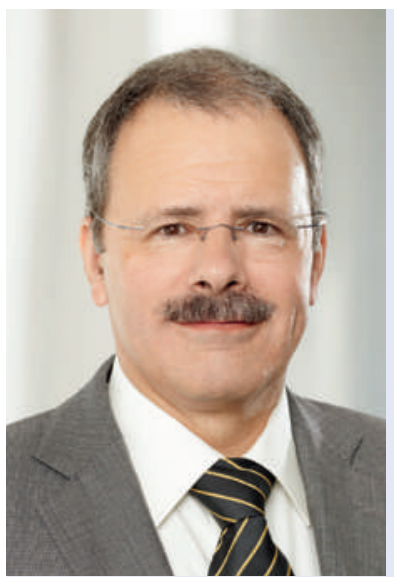

Dr. med.

Jürg Schlup, Präsident FMH das NEJM, aber doch eine Schweizer Kost, die sich jedes Jahr besser zu profilieren weiss.

Wir wünschen Ihnen viel Freude an diesem neuen Service für die FMH-Mitglieder!

Dr. med. Jürg Schlup, Präsident FMH

Prof. Dr. med. André P. Perruchoud, Chefredaktor SMW

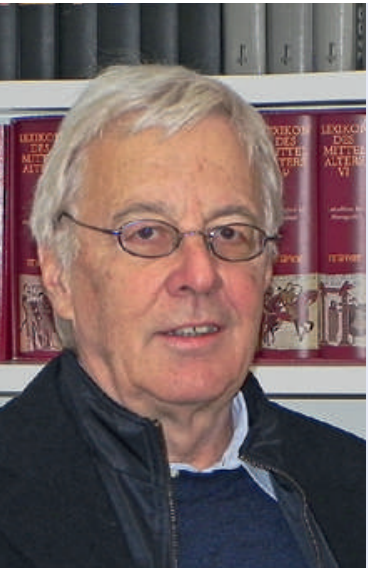

Prof. Dr. med.

André P. Perruchoud, Chefredaktor SMW 